\title{
Patient inclusion in transfusion medicine: current perspectives
}

This article was published in the following Dove Press journal:

International Journal of Clinical Transfusion Medicine

13 January 2015

Number of times this article has been viewed

\section{Mark T Friedman' \\ Peyman Bizargity' \\ Sandra Gilmore ${ }^{2}$ \\ Arnold Friedman ${ }^{3}$}

'Blood Bank and Transfusion Medicine Service, Department of Pathology, Mount Sinai St Luke's-Roosevelt Hospital Center, ${ }^{2}$ Patient Blood Management Program, Center for Blood Management and Bloodless Medicine and Surgery, Mount Sinai Beth Israel Medical Center, ${ }^{3}$ Department of Obstetrics, Gynecology, and Reproductive Science, Icahn School of Medicine at Mount Sinai, New York, NY, USA

\section{Video abstract}

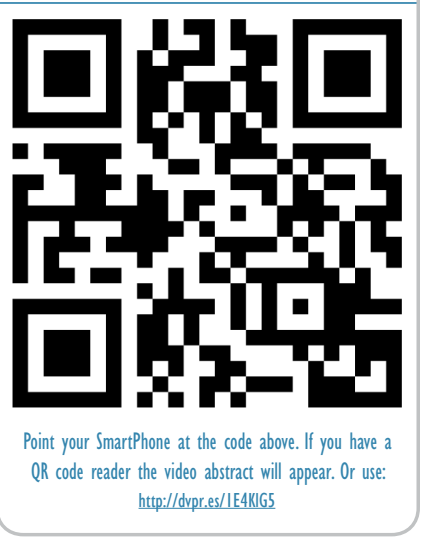

Correspondence: Mark T Friedman Blood Bank and Transfusion Medicine Service, Department of Pathology, Mount Sinai St Luke's-Roosevelt Hospital Center, I000 Tenth Avenue, New York, NY 10019 , USA

Tel +I 2125237242

Fax + I 2125236394

Email markfriedman@chpnet.org
Abstract: Patients may have differing perceptions about blood transfusions based on their backgrounds, values, education levels, or cultural or religious beliefs, which may or may not be accurate. Unfortunately, despite the fact that transfusions are associated with a number of infectious and noninfectious risks, and in spite of the fact that there are ethical, accreditation, and regulatory requirements to provide information regarding transfusion risks, benefits, and alternatives to patients, transfusion consent remains inconsistently obtained. This can partly be attributed to the fact that clinicians may take on a paternalistic approach to transfusion decisions as well as to the fact that many clinicians have knowledge gaps in transfusion medicine that prevent them from obtaining transfusion consent adequately. As a result, unlike the case with other medical and surgical therapies, most patients are not included in the making of informed decisions regarding the need for transfusion versus alternative therapies, leading to many situations in which the transfusions provide little benefit to them. Recently however, a number of organizations, such as the American Association of Blood Banks and The Joint Commission in the US, have promoted multidisciplinary, evidence-based treatment strategies that aim to minimize the need for blood transfusion, the so-called patient blood management (PBM) protocols. PBM strategies are expected to improve blood utilization through optimization of patients who may need blood transfusions via measures such as preoperative anemia management, intraoperative cell salvage, and improved transfusion guidelines. PBM strategies also focus on enhanced requirements for transfusion education and shared decision making, including informed consent and, thus, promote a patient-centered approach as defined by the Institute of Medicine.

Keywords: informed consent, patient blood management, patient-centered approach, patient communication, shared decision making

\section{Introduction}

"The time is not yet at hand when final statements as to the definite indications for direct transfusion of blood can be made."' This statement was authored over a century ago, yet it is remarkable that even today we find that many transfusions are administered without a clear indication as transfusion triggers cannot be so precisely defined. Blood transfusion, nevertheless, remains one of the most common interventions performed in the hospital setting, with an estimated 11 million units of red blood cells (RBCs) transfused in the US in $2013 .^{2}$ But through the years, it has become an increasingly alarming fact that many transfusions given in the hospital are not necessary, with an astounding $59 \%$ of transfusions found to be inappropriate in one recent study, while other studies have demonstrated significant variability in transfusion rates among physicians performing the same surgical procedures. ${ }^{3-5}$ Furthermore, it is evident that 
transfusion rates and practices vary among nations, making this a global concern. ${ }^{6,7}$ Because of these issues, a number of organizations, including The Joint Commission (formerly, the Joint Commission on Accreditation of Healthcare Organizations [JCAHO]), the American Medical Association, and the Society for Hospital Medicine, have identified blood overutilization as a high-priority quality and safety concern. ${ }^{8}$ To that end, what randomized, controlled trials (RCTs) have been able to demonstrate over the past 15 years, dating back to the landmark study of transfusion requirements in critical care patients by Hèbert et al, ${ }^{9}$ is that less transfusion (ie, restrictive transfusion strategy) is at least as good as, if not better than, more transfusion (ie, liberal transfusion strategy) in terms of morbidity and mortality outcomes, and that these results have been consistent across different patient populations (with $>7,000$ patients enrolled in clinical trials), including pediatric patients, cardiac surgery patients, elderly hip-fracture patients, and patients with upper gastrointestinal bleeding. ${ }^{10-14}$ Meanwhile, traditional infectious risks of transfusion, such as human immunodeficiency virus (HIV) and viral hepatitis (hepatitis $\mathrm{B}$ and $\mathrm{C}$ ), have been vastly reduced through improved assays; noninfectious risks and complications such as transfusion-related acute lung injury (TRALI), iron overload, and the long-term risk of transfusion-related immunomodulation (TRIM) have become more prominent while emerging transmissible risks, such as bacterial contamination of platelet components, West Nile virus, Chagas disease, babesiosis, hepatitis E virus, and spongiform transmissible agents (ie, the agent of mad cow disease), among others, are being increasingly scrutinized.

Clinical guidelines, such as the one from the American Society of Anesthesiologists or, more recently, from the Society of Critical Care Medicine and the AABB (formerly, the American Association of Blood Banks), were published in order to improve transfusion practices and reduce overutilization of blood. ${ }^{15-17}$ However, the practical impact of such guidelines, which focus on hemoglobin trigger values to guide transfusion therapy, was quite minimal in that the approach tended to be unilateral (ie, adopted by hospital transfusion services but not accepted by clinicians who continued to transfuse based on past practice while often justifying out-of-guideline transfusions when challenged by the claim that their patient population is "sicker") and lacked other key elements such as transfusion education and a patient-centered approach. Thus, more recent efforts to curb inappropriate blood utilization have engendered the promotion of patient blood management (PBM) strategies. This article further discusses patient perspectives on transfusion and PBM strategies as a patient-centered approach in a shared decision-making (hence, patient inclusion) model toward optimization of blood utilization practices.

\section{Patient perspectives on blood transfusion and informed consent}

Although, for many patients, transfusion is a life-saving or life-sustaining treatment, for many others, it may evoke a lingering negative image and anxiety because of its association with HIV transmission, particularly during the early days of the epidemic in the 1980s and 1990s when there were several high-profile cases in the news. Table 1 outlines factors affecting patient perceptions of blood transfusion. In fact, one recent study found that nearly $9 \%$ of patients believed that transmission of HIV and hepatitis occurs very frequently. ${ }^{18}$ However, perception of transfusion risk may differ depending on patient sex, race, and education level, with higher risk perception generally found in female, nonwhite, and less-educated patients. ${ }^{18,19}$ Moreover, there appear to be differences in the way that patients and clinicians perceive blood transfusions, with one study finding greater perception of risks associated with transfusion among physicians, while an earlier study found less perception of risks among physicians than patients. ${ }^{19,20}$ However, although transfusion has become much safer through regulatory measures, donor screening, improvements in quality of the blood supply, and because of highly sensitive assays for infectious diseases, especially HIV and hepatitis C, whereby the risk has been reduced to $<1$ per 1-2,000,000 units transfused, the risks of transfusion can never be entirely eliminated. ${ }^{21,22}$ This particularly holds true for certain risks and complications in which the mechanisms are not yet fully understood, such as TRALI and TRIM, while for many of the infectious risks, assays are not yet available for blood donor testing and perhaps would be prohibitively costly to test for all of them. In addition, there remains the possibility that previously unidentified risks may emerge to threaten the safety of the blood supply. Yet for other patients, there may be cultural or religious reasons underlying

Table I Factors affecting patient perception of blood transfusion and related references

\begin{tabular}{ll}
\hline Factors & References \\
\hline I. Lingering negative association with the & Vetter ${ }^{18}$ \\
HIV epidemics of the 1980 s and $1990 \mathrm{~s}$ & \\
$\begin{array}{l}\text { 2. Patient sex, race, and education level } \\
\text { 3. Differences in physician's risk perception } \\
\text { of transfusion }\end{array}$ & Vetter, $^{18}$ Finucane $^{19}$ \\
4. Patient's cultural or religious background,${ }^{19}$ Lee $^{20}$ \\
\hline
\end{tabular}

Abbreviation: HIV, human immunodeficiency virus. 
their preference to avoid blood transfusion, as in the case of Jehovah's Witnesses. For these reasons, it is important that clinicians discuss all planned transfusions with their patients and obtain proper informed consent.

Informed consent is a "fundamental tenet of the US health care system," with the principle, based on a pivotal court case, that "every human being of adult age and sound mind has a right to determine what shall be done with his own body."23 The term "informed consent" itself achieved medical and legal currency from a 1957 California case in which a patient charged that his physicians failed to inform him of the risks involved in performing translumbar aortography, after which the patient became paralyzed. ${ }^{24}$ Furthermore, the Institute of Medicine (IOM), in naming patient centeredness, defined as "providing care that is respectful of and responsive to individual patient preferences, needs, and values, and ensuring that patient values guide all clinical decisions," as one of its six core attributes of a high-quality health system and encourages dialogue between physicians and patients in the decision-making process. ${ }^{25}$ In light of this, AABB Standard 5.26.1 states that the "transfusion service medical director shall participate in the development of policies, processes, and procedures regarding recipient consent for transfusion" and that at a minimum, the elements of consent shall include 1) a description of the risks, benefits, and treatment alternatives (including nontreatment), 2) the opportunity to ask questions, and 3) the right to accept or refuse transfusion. ${ }^{26}$ Likewise, the Joint Commission, an organization in the US that accredits health care organizations, promotes informed consent for blood transfusion through its Patient Blood Management Initiatives, ${ }^{27}$ which hospitals could opt to use to evaluate processes around transfusions and, more recently, through its proposed Blood Management Certification program. ${ }^{28}$ Region-specific regulations, such as California's Paul Gann Blood Safety Act, may also require elements of informed consent whenever transfusion may be reasonably required. ${ }^{29}$

As simple as the concept of informed consent may seem (ie, providing information prior to a planned treatment with acknowledgment and agreement on the course of action to take), there are a number of considerations that may negatively impact the effectiveness of the consent process (Table 2). Physician education and knowledge of transfusion medicine is one such factor. Several recent studies have shown that physicians have significant knowledge gaps in transfusion medicine and that the knowledge gaps correlate with lack of formal education in transfusion medicine. ${ }^{18,30,31}$ Knowledge gaps may skew information that clinicians are able to provide
Table 2 Factors affecting transfusion consent/shared decision making and related references

\begin{tabular}{ll}
\hline Factors & References \\
\hline $\begin{array}{l}\text { I. Physician's knowledge deficits } \\
\text { in transfusion medicine }\end{array}$ & $\begin{array}{l}\text { Vetter, }{ }^{18} \text { Arinsburg, }{ }^{30} \\
\text { O'Brien }\end{array}$ \\
$\begin{array}{l}\text { 2. Paternalistic approach to transfusion } \\
\text { by physicians }\end{array}$ & ${\text { Schenker, }{ }^{23} \text { Adams }^{33}}^{33}$ \\
3. Quantity of information discussed & Schenker, ${ }^{23}$ Davis ${ }^{34}$ \\
4. Use of abbreviated transfusion & New York State Council \\
consent form for surgical versus & on Human Blood and \\
medical patients & Transfusion Services ${ }^{37}$ \\
$\begin{array}{l}\text { 5. Patient recall of discussed information } \\
\text { 6. Timing of transfusion consent }\end{array}$ & $\begin{array}{l}\text { Turner }{ }^{38} \\
\text { (ie, day of elective procedure) }\end{array}$ \\
\hline
\end{tabular}

to their patients. In that regard, one study found that physicians overestimated certain transfusion risks such as febrile, allergic, and hemolytic reactions, while another found that risks were understated compared with benefits, noting that some medicine residents in the study falsely cited wound healing as a benefit while TRALI, for example, was rarely mentioned as a risk. ${ }^{18,32}$ Physicians who take on a paternalistic approach to informed consent may also present skewed information favoring their preferred treatment; Adams and Tolich ${ }^{33}$ found that the patients interviewed in their study reported that because a physician had decided that a transfusion would take place, they did not understand that there were other options for treating their anemia, and they had concerns about the safety of the blood supply which were inadequately explained by written materials presented to them.

The quantity of information discussed may also affect patient comprehension and retention of the information. Schenker and $\mathrm{Meise}^{23}$ noted that more is not always better. That is to say, as suggested by Davis et al, ${ }^{34}$ that patients may have a variety of needs for more or less detailed information. But while few, if any, would argue that the risks of HIV and hepatitis transmission, as well as that of TRALI and hemolytic reactions, should be discussed among other well-known transfusion risks, less certain is the question whether other rare but fatal risks should be included. For example, Hart et $\mathrm{a}^{35}$ from the University of Alberta in Canada ascertained that variant Creutzfeldt-Jakob disease should be discussed, even though prion transmission through blood transfusion was only theoretical at the time of their report; moreover, it should be noted that several cases have since been reported, but none outside of the UK to date. ${ }^{36}$ Also troubling is the fact that in many hospital facilities across the US, the transfusion consent process is different for surgical patients from that for medical patients, with the former receiving only a cursory line-item signature to accept blood transfusion bundled 
within the larger context of the surgical consent form. To address this, the New York State Council on Human Blood and Transfusion Services recommended separate documentation for transfusion consent from consent related to other treatment; ${ }^{37}$ however, unfortunately, this recommendation largely goes unheeded. Yet, even in the case that a patient may reasonably understand the information provided, the information may be quickly forgotten as was evident in a study of patients who were asked to give consent for joint replacement surgery. ${ }^{38}$ Finally, timing of transfusion consent may also negatively affect effectiveness. In their study, Eisenstaedt et $\mathrm{al}^{39}$ found that even for elective surgical procedures, most institutions obtained transfusion consent on the day before or the day of the surgery when anxiety and other factors may impede learning opportunities. In fact, what Schenker and Meisel $^{23}$ aptly point out is that the consent process often occurs after the decision has already been made to go ahead with the procedure, leaving patients feeling pressured to sign the consent form so as not to cause delay. Meanwhile, Friedman et $\mathrm{al}^{32}$ found that the transfusion consent discussion did not last longer than 10 minutes in the majority of cases surveyed in their study, clearly inadequate time for most patients to make a fully informed decision; in spite of this, remarkably only $7 \%$ of the patients cited the need for more time as a means to improve the transfusion consent process.

\section{PBM and the patient as a member of the clinical transfusion team}

PBM strategies, such as those promoted by the AABB, the Joint Commission, and the Society for the Advancement of Blood Management (SABM), aim to optimize transfusion practices. These evidence-based strategies take on a patient-centered approach and are beneficial in minimizing blood overutilization, reducing transfusion risks to patients, improving patient outcomes, and reducing transfusion costs to society at large, which, as per SABM, has reached a staggering $\$ 8.4$ billion USD for unnecessary transfusions. ${ }^{40}$ Effective PBM would also conserve blood products for patients who may really benefit from them as it should be noted that the rate of blood donation in the US dropped to $4.5 \%$ in 2011 for persons aged 16-64 years, the lowest donation rate since $1997 .^{2} \mathrm{PBM}$ has been cited as one of the ten key advances in transfusion medicine over the past 50 years. ${ }^{41}$ The four guiding principles of effective PBM are anemia management, coagulation optimization, blood conservation, and patient-centered decision making. ${ }^{8}$ But of significance, PBM strategies are not a unilateral approach; rather, they involve a group of multidisciplinary, multimodality services and specialists at many levels working together, including the hospital transfusion service, transfusion safety officers, hospital administrators, nurses, perfusionists (who provide Cell Saver services during surgery), pharmacists, anesthesiologists, and other medical and surgical specialists. PBM strategies also offer a variety of treatment options used to prevent or treat anemia to minimize the need for blood transfusion, which are important to understand within the context of a patient-centered approach as discussed below, though a more detailed discussion of these options is beyond the scope of this review but can be found elsewhere. ${ }^{8,42}$

Preoperative anemia has been associated with increased risk of allogeneic blood transfusion and postoperative morbidity and mortality. ${ }^{42,43}$ Therefore, screening for anemia and coagulopathy, in addition to other high-risk patient factors noted by Ferraris et $\mathrm{al}^{42}$ such as advanced age and comorbidities, prior to planned elective surgical procedures is of high importance in order to ensure proper workup and treatment, including nutritional support (dietary iron and vitamins), administration of iron infusions or erythropoiesis-stimulating agents (ESAs), as well as a review of all medications and supplements/herbs (which may interfere with coagulation) taken by the patient. Screening patients early on, well before the planned procedure, can also stimulate discussion about the role of blood product transfusion and allows patients to express their views of transfusion in a shared decision-making model (Figure 1). Shared decision making empowers patients to be involved in their own treatment decisions, effectively enabling them to act as a member of the clinical transfusion team, frequently culminating in a formal informed consent. However, Vetter et $\mathrm{al}^{18}$ note that shared decision making is a broader concept than informed consent, with three essential elements: 1) recognizing and acknowledging that a decision is required; 2) knowing and understanding the best available evidence; and 3) incorporating the patient's values into the decision. Many patients will have concerns and even misconceptions about the safety of the blood supply, which may deter them from accepting blood transfusions. ${ }^{18,19}$ Some patients may express interest in pre-donating their own blood (ie, autologous blood donation) or in having family members or friends donate blood for them in case of need (ie, directed or designated blood donation). However, autologous blood donation has been on the decline and is associated with higher risk of decreased postoperative hematocrits, increased risk of transfusion, and increased cost, as well as increased wastage of blood because many autologous units are never used.,44-47 Therefore, it is not uniformly recommended as 


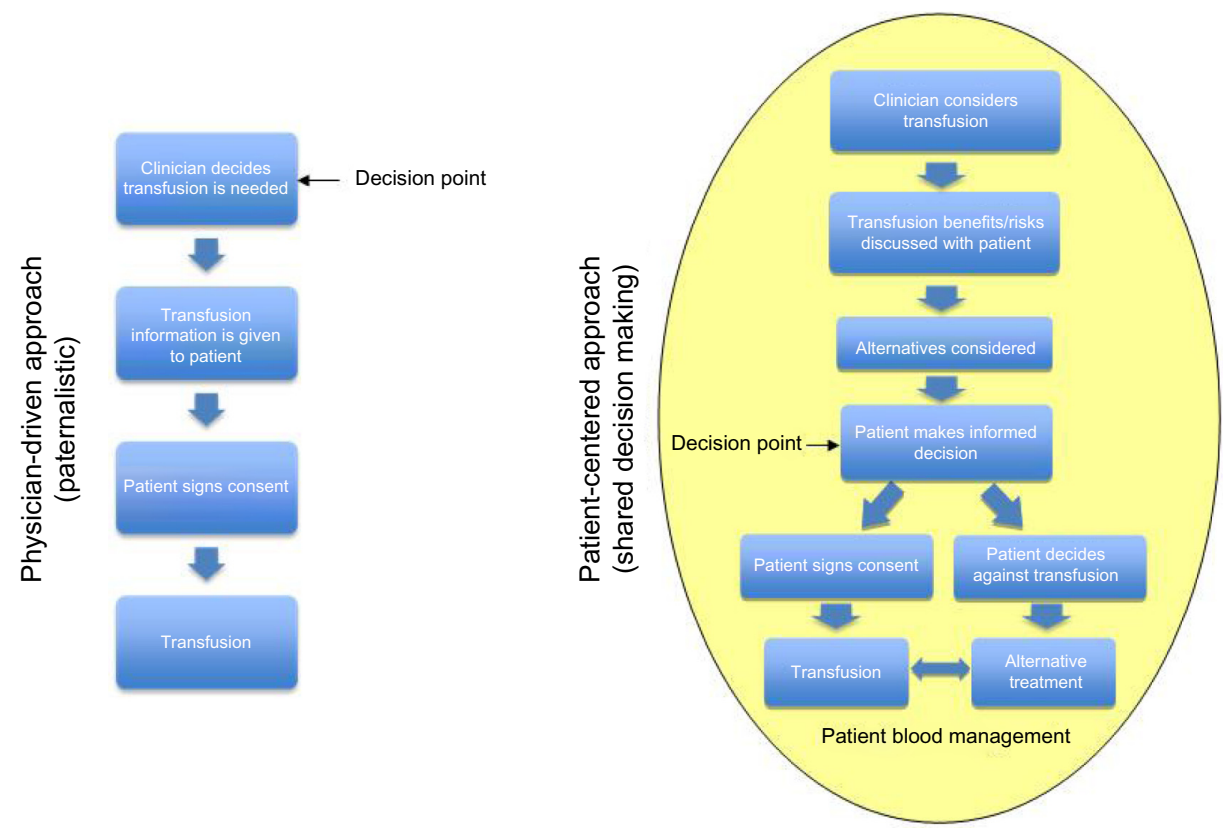

Figure I PDA versus PCA during blood transfusion.

Notes: In PCA, the transfusion decision point occurs after patient discussion, while in PDA, it occurs beforehand. PCA is optimal within a patient blood management environment that educates physicians, minimizes transfusion, offers alternatives, and leads to improved patient safety and clinical outcomes with reduced overall costs. Note that, in PCA, alternative treatment and transfusion are not necessarily mutually exclusive but that alternative treatment may reduce the amount of transfusions needed.

Abbreviations: PDA, physician-driven approach; PCA, patient-centered approach.

a blood conservation strategy. Meanwhile, directed blood donations are not considered to be any safer than blood from volunteer blood donors and have added logistical problems such as confidentialty. ${ }^{48}$

Iron infusions may be appropriate for some patients who are found to be anemic though physicians may be reluctant to prescribe parenteral iron because of past problems, such as anaphylaxis and fatalities, associated with older iron preparations, particularly high-molecular-weight iron dextran. ${ }^{49}$ Newer preparations - low-molecular-weight iron dextran, iron sucrose, and ferric gluconate - have improved safety profiles so that physicians should be encouraged to utilize parenteral iron as a means to correct anemia and avoid transfusions in their patients. ${ }^{50}$ ESAs may also be given with or without iron and have shown benefit in reducing transfusion requirements though they are costly and have associated cardiovascular risks, particularly at higher target hemoglobin levels..$^{51,52}$

Intra- and postoperative blood conservation techniques, including the application of acute normovolemic hemodilution (ANH), cell salvage, topical hemostatic and sealant agents, and antifibrinolytic agents, may also be discussed with patients and used when appropriate. ANH, a method in which whole blood is collected and replaced by crystalloid and/or colloid fluid with retransfusion of the whole blood at the end of the surgical procedure, has been successfully used in some cases but is not uniformly recommended. ${ }^{53}$ Segal et al, ${ }^{54}$ for example, found only modest benefit of preoperative ANH in their meta-analysis. Intraoperative cell salvage may be considered for procedures associated with significant blood loss (ie, $>1,000 \mathrm{~mL}$ or $20 \%$ of blood volume), ${ }^{55}$ though Esper and Waters ${ }^{56}$ suggest that cell salvage may be cost effective and should be considered with even smaller amounts of blood loss than previously recommended. Likewise, postoperative cell salvage may be useful in select cases. ${ }^{57}$ However, cell salvage, along with ESAs, may not be cost effective for some types of procedures in which significant blood loss is expected (such as total hip and knee arthroplasties), and there are a number of potential contraindications, such as contamination of the salvaged blood by urine, bowel contents, infection, amniotic fluid, malignancy, etc, or an underlying hematological condition of the patient (eg, sickle cell disease) that may prevent use of the cell saver; these issues should be discussed with the patient. ${ }^{55,58}$ Topical hemostatic and sealant agents have also been found to be effective in surgical blood conservation. ${ }^{59}$ Meanwhile, there has been evidence for many years that the antifibrinolytic agents tranexamic acid and epsilon-aminocaproic acid reduce the need for blood transfusion in surgery (particularly cardiac surgery), with one review showing that tranexamic acid reduced blood transfusion in elective surgery by $34 \%{ }^{60-62}$ Another antifibrinolytic agent, aprotinin, was withdrawn from the market 
after studies revealed increased risk of serious end-organ damage and death. ${ }^{63,64}$ Use of surgical technologies (such as electrosurgery, argon beam coagulation, and radiofrequency technology) and bedside coagulation monitoring devices, such as thromboelastography $\left(\mathrm{TEG}^{\circledR}\right.$; Haemonetics, Braintree, MA, USA), or thromboelastometry (ROTEM ${ }^{\circledR}$; TEM Innovations GmbH, Munich, Germany), have also been shown to be useful in aiding hemostasis to minimize blood loss. ${ }^{8,65}$ Lastly, strict attention should be paid to minimizing blood draws for laboratory tests pre- and postoperatively as excessive phlebotomy has been known to greatly contribute to anemia. ${ }^{66,67}$

It is apt to mention here that the possibility of undertransfusion should not be overlooked, as noted by Hibbs et al, ${ }^{68}$ who suggest that utilization review include such monitoring. Although these authors did not find evidence of undertransfusion in their study patients with either low hemoglobin or low platelet counts, they recommend clear justification for the withholding of transfusion just the same as for administering a transfusion.

\section{Current evidence for patient inclusion to optimize outcomes and opportunities for improvement}

In its critical report, the IOM stated that the "US health care delivery system does not provide consistent, high-quality medical care to all people." ${ }^{25}$ It further went on to recommend that the health care delivery system should be reorganized to provide care that is safe, effective, and efficient and that it must be evidence based as well as respectful of patients' values (ie, patient centered). The report further advocated that knowledge must be shared via open communication between clinicians and patients and that shared decisions must also be evidence based. In a previous report, the IOM concluded that perhaps as many as 98,000 persons die each year in US hospitals as a result of preventable medical errors. ${ }^{69}$ Subsequent to this, The Joint Commission established the National Patient Safety Goals, effective January 2003, intended to reduce key medical errors. ${ }^{70}$ The inclusion of patients in their health care decisions, along with clinician knowledge of evidence-based medicine, can promote improved patient safety and lead to improved clinical outcomes and patient satisfaction, as demonstrated by experience within and outside the realm of transfusion. ${ }^{42,71,72}$ Yet, despite these lofty reports and safety goals, progress in the way of transfusion medicine has been slow to develop. Table 3 outlines factors that need to be looked into to improve transfusion practice. Murphy et $\mathrm{al}^{73}$ identified overly optimistic
Table 3 Factors to be looked into to improve transfusion practice and related references

\begin{tabular}{|c|c|}
\hline Factors & References \\
\hline $\begin{array}{l}\text { I. Education of clinicians and nurses } \\
\text { on transfusion procedures } \\
\text { to reduce knowledge deficits }\end{array}$ & Toy, ${ }^{75}$ Kaur ${ }^{76}$ Haspel $^{77}$ \\
\hline $\begin{array}{l}\text { 2. Dissemination of updated } \\
\text { evidence-based transfusion guidelines }\end{array}$ & Toy 75 \\
\hline $\begin{array}{l}\text { 3. Prospective audits of blood } \\
\text { product requests }\end{array}$ & Toy 75 \\
\hline $\begin{array}{l}\text { 4. Use of computerized } \\
\text { physician-order entry }\end{array}$ & $\begin{array}{l}\text { Rothschild, }^{78} \text { Goodnough, } \\
\text { Yerrabothola }^{70}\end{array}$ \\
\hline $\begin{array}{l}\text { 5. Use of transfusion avoidance/blood } \\
\text { conservation strategies }\end{array}$ & $\begin{array}{l}\text { Feagan, }{ }^{50} \text { Steensma, }{ }^{51} \\
\text { Lindstrom, }^{53} \text { Ashworth, }{ }^{55}\end{array}$ \\
\hline (ie, preoperative anemia screening, & Esper, ${ }^{56}$ Ozawa, ${ }^{59}$ \\
\hline iron/ESA infusion, intraoperative & Ker, ${ }^{60}$ Henry, ${ }^{61}$ \\
\hline cell salvage, etc) & $\begin{array}{l}\text { Brown, }{ }^{62} \text { Bolliger, }{ }^{65} \\
\text { Thavendiranathan, }{ }^{66} \text { Chant }^{67}\end{array}$ \\
\hline $\begin{array}{l}\text { 6. Use of multicomponent apheresis } \\
\text { transfusion strategy (patient-centric } \\
\text { paradigm) }\end{array}$ & Vamvakas $^{74}$ \\
\hline $\begin{array}{l}\text { 7. Timely transfusion consent } \\
\text { and shared decision making }\end{array}$ & Schenker, ${ }^{23}$ Eisenstaedt ${ }^{39}$ \\
\hline $\begin{array}{l}\text { 8. Use of TQM approach } \\
\text { and systematic reviews }\end{array}$ & $\begin{array}{l}\text { Ferraris, }{ }^{42} \text { Dorée, }{ }^{85} \\
\text { Wilkinson }{ }^{86}\end{array}$ \\
\hline $\begin{array}{l}\text { 9. Evidence-based implementation } \\
\text { to bridge gap between high-quality } \\
\text { evidence and clinical practice }\end{array}$ & Lorencatto ${ }^{87}$ \\
\hline
\end{tabular}

Abbreviations: ESA, erythropoiesis-stimulating agent; TQM, total quality management.

perceptions of actual transfusion practices, knowledge deficits, prescriber variation in transfusion thresholds, and limited explicit communication (ie, transfusion thresholds rarely discussed on clinical rounds) as important provider and system barriers to evidence-based RBC transfusion practices. Meanwhile, Vamvakas ${ }^{74}$ has advocated for progress via the implementation of a transfusion strategy that would utilize multicomponent apheresis (ie, multiple blood components collected from one donor intended for the same recipient) along with PBM as a means to reduce donor exposure and achieve as-low-as-reasonably achievable risk, a strategy he termed the "patient-centric paradigm" (as opposed to the "component-centric paradigm").

As noted above, clinician knowledge gaps in transfusion medicine persist, hindering them from practicing effective evidence-based medicine despite recommendations from RCTs and updated transfusion guidelines. Toy ${ }^{75}$ found that one-on-one meetings with physicians, scheduled teaching conferences, prospective audits of ordered transfusions along with daily clinical rounds of transfused patients, and transfusion guidelines in the operating room were effective measures in providing transfusion education. However, these methods, in particular those involving prospective audits and 
daily patient rounds, are very time consuming and may not be practical for many hospital transfusion services to implement. Meanwhile, Kaur et al ${ }^{76}$ recommended transfusion medicine training at the undergraduate level, with regular mandatory training of interns, residents, and nurses. Toward that end, Haspel et $\mathrm{al}^{77}$ reported that a greater amount of medical school or higher-quality residency training in transfusion medicine was associated with increased transfusion medicine knowledge on an international level, as measured on a standardized survey. Computerized physician-order entry (CPOE) guides have also been shown to be effective, in conjunction with education, in reducing inappropriate transfusions. ${ }^{78-80}$ In the authors' experience within our own PBM program, we have found that a combination of strategies, including prospective audits of RBC transfusions, educational seminars, updated transfusion guidelines, and the use of CPOE guides, have effectively improved transfusion practices by physicians, with a decrease in the number of transfused $\mathrm{RBC}$ units by approximately $33 \%$, even when adjusted for patient discharges, representing a significant decrease in inappropriate transfusions and progress toward evidence-based transfusion practices (unpublished data).

Yet another barrier to shared decision making and improved transfusion practice is that patients do not receive timely and appropriate information regarding the benefits, risks, and alternatives to transfusion. In fact, studies have shown that even when standardized written information is available, it is often not distributed to patients..$^{32,81}$ Clearly, ensuring that patients receive intended informational pamphlets and materials is merely a first step as there is no guarantee that patients will read or understand the information. Thus, others have proposed use of read back, in which a patient is asked to repeat discussed information to ensure comprehension, the viewing of an informational video prior to transfusion, and the use of an evidence-based decision aid to guide clinicians and patients through the decision. ${ }^{23,81,82}$ Furthermore, patients must receive the transfusion information at a time when they will be able to understand the risks and benefits and have time to undergo appropriate alternatives, such as iron and ESA therapy. Yet, differences in the way that physicians and patients perceive transfusions and associated risks as noted above, as well as ethnic and racial disparities in the way that health care is administered, pose significant challenges toward improving transfusion practices in a patient-centered and shared decision-making model but represent opportunities for improvement. ${ }^{18,20,83,84}$ Additionally, introduction of newer technologies such as point-of-care coagulation testing (eg, thromboelastography) can improve patient laboratory monitoring and, thus, appropriate use of blood products.

Of note, in the wake of increasing recommendations for blood management protocols, a number of transfusion utilization consulting and external review services have cropped up in recent times to assist health care organizations in improving their transfusion practices through proprietary utilization data analysis, case review, and educational sessions. Such services perhaps can assist in establishing a total quality management approach, defined as continuous assessment of quality improvement, to blood conservation as recommended by Ferraris et al. ${ }^{42}$ Though such services do carry significant upfront charges, the long-term savings, along with increased patient satisfaction and safety, can justify their employment to hospital administrators.

Use of systematic reviews may also improve the practice of transfusion medicine. In light of the vast expansion of transfusion medicine as a specialty, given the increasing number of transfusion-related therapies along with blood conservation techniques as well as the movement toward evidence-based medicine, it is understandable that the number of clinical studies involving transfusion therapy has greatly increased over the past 10-15 years. As such, Murphy et a ${ }^{85,86}$ have performed several systematic reviews covering international RCTs across different aspects of transfusion. Systematic reviews allow for a better understanding of the totality of the evidence base, are less biased in their approach toward their review of a subject, and make the results of different clinical trials much more accessible to clinicians. ${ }^{85}$ However, while some areas of transfusion, such as transfusion triggers and RBC transfusion in critical care, have been covered by systematic reviews, many other areas have not been covered. A recent systematic review of RBC transfusions, ${ }^{86}$ covering 142 RCTs over 11 different clinical specialties and 10 types of interventions (eg, leukoreduced $\mathrm{RBCs}$, transfusion triggers, $\mathrm{RBC}$ transfusion versus no transfusion, etc), reported that the quality of many of the RCTs is poor, particularly older studies prior to 2001, and that there are clinically relevant gaps in the evidence base. The authors recommended that future research be directed toward trigger trials, storage age of blood, transfusion versus no transfusion, targeting specific specialty areas with lack of RCTs relative to their use of blood transfusion (eg, obstetrics and gynecology, oncology), and updating systematic reviews to include areas lacking such reviews of identified RCTs (eg, solid organ transplant).

Finally, Lorencatto et $\mathrm{al}^{87}$ espouse the concept that bridging the gap between high-quality evidence and current 
clinical practice in transfusion medicine will require evidence-based implementation. These authors note that implementation science is an emerging field of study focusing on the investigation of methods for promoting the systematic uptake of evidence into routine clinical practice, which has played a central role in developing and evaluating interventions to change clinical practice and minimize the so-called "evidence-practice gap."

\section{Conclusion}

Despite published evidence-based medicine, transfusion practices remain far from ideal. Implementation of a patient-centered, shared decision-making approach to transfusion within the context of a PBM program, or perhaps the "patient-centric paradigm" envisioned by Vamvakas, ${ }^{74}$ will be of great benefit to patients, with improved outcomes, safety, satisfaction, and cost savings to health care organizations. Evidence-based implementation of strategies that involve provision of transfusion education to clinicians, including medical students, residents, nurses, and others involved in the transfusion of blood to patients, use of updated transfusion guidelines, use of CPOE and decision-support aids, blood utilization review, and timely and informative transfusion consent, as well as dissemination of transfusion alternatives and blood conservation techniques, in a multidisciplinary, teamwork approach will be required. Ultimately, however, we believe that such implementation will necessitate a major paradigm shift in the US health care culture from a system in which transfusion is viewed by the clinicians as a first-line, quick-fix treatment option for the anemic patient to one in which transfusion becomes an option after careful discussion with the patient. Nevertheless, through the efforts of organizations such as the Joint Commission, the AABB, and the SABM, we are encouraged that this paradigm shift has begun, as evidenced by reports of successful PBM programs as well as a steady decline in transfusions across the US over the past few years. ${ }^{88,89}$

\section{Disclosure}

The authors report no conflicts of interest in this work.

\section{References}

1. JAMA. The practical value of transfusion of direct transfusion of blood. JAMA 100 years ago. JAMA. 2012;308:746.

2. US Department of Health and Human Services. The 2011 national blood collection and utilization report; 2011. Available from: http://www.hhs. gov/ash/bloodsafety/2011-nbcus.pdf. Accessed October 12, 2014.

3. Shander A, Fink A, Javidroozi M, et al; International Consensus Conference on Transfusion Outcomes Group. Appropriateness of allogeneic red blood cell transfusion: the international consensus conference on transfusion outcomes. Transfus Med Rev. 2011;25(3): 232-246e253.
4. Frank SM, Savage WJ, Rothschild JA, et al. Variability in blood and blood component utilization as assessed by an anesthesia information management system. Anesthesiology. 2012;117(1):99-106.

5. Gombotz H, Rehak PH, Shander A, Hofmann A. Blood use in elective surgery: the Austrian benchmark study. Transfusion. 2007;47(8): $1468-1480$.

6. Cobain TJ, Vamvakas EC, Wells A, Titlestad K. A survey of the demographics of blood use. Transfus Med. 2007;17(1):1-15.

7. Gombotz H, Rehak PH, Shander A, Hofmann A. The second Austrian benchmark study for blood use in elective surgery: results and practice change. Transfusion. 2014;54(10 pt 2):2646-2657.

8. Hohmuth B, Ozawa S, Ashton M, Melseth RL. Patient-centered blood management. J Hosp Med. 2014;9(1):60-65.

9. Hèbert PC, Wells G, Blajchman MA, et al. A multicenter, randomized, controlled clinical trial of transfusion requirements in critical care. Transfusion requirements in critical care investigators, Canadian critical care trials group. N Engl J Med. 1999;340(6):409-417.

10. Carson JL, Patel MS. Red blood cell transfusion thresholds: can we go even lower? Transfusion. 2014;54(10 pt 2):2593-2594.

11. Lacroix J, Hebert PC, Hutchison JS, et al; TRIPICU Investigators; Canadian Critical Care Trials Group; Pediatric Acute Lung Injury and Sepsis Investigators Network. Transfusion strategies for patients in pediatric intensive care units. $N$ Engl J Med. 2007;356(16):1609-1619.

12. Hajjar LA, Vincent JL, Galas FR, et al. Transfusion requirements after cardiac surgery: the TRACS randomized controlled trial. JAMA. 2010;304(14):1559-1567.

13. Carson JL, Terrin ML, Noveck H, et al; FOCUS Investigators. Liberal or restrictive transfusion in high-risk patients after hip surgery. $N$ Engl J Med. 2011;365(26):2453-2462.

14. Villanueva C, Colomo A, Bosch A, et al. Transfusion strategies for acute upper gastrointestinal bleeding. N Engl J Med. 2013;368(1):11-21.

15. Practice Guidelines for blood component therapy: a report by the American society of anesthesiologists task force on blood component therapy. Anesthesiology. 1996;84(3):732-747.

16. Napolitano LM, Kurek S, Luchette FA, et al; American College of Critical Care Medicine of the Society of Critical Care Medicine; Eastern Association for the Surgery of Trauma Practice Management Workgroup. Clinical practice guideline: red blood cell transfusion in adult trauma and critical care. Crit Care Med. 2009;37(12):3124-3157.

17. Carson JL, Grossman BJ, Kleinman S, et al; Clinical Transfusion Medicine Committee of the AABB. Red blood cell transfusion: a clinical practice guideline from the AABB. Ann Intern Med. 2012;157(1): 49-58.

18. Vetter TR, Adhami LF, Porterfield JR Jr, Marques MB. Perceptions about blood transfusion: a survey of surgical patients and their anesthesiologists and surgeons. Anesth Analg. 2014;118(6):1301-1308.

19. Finucane ML, Slovic P, Mertz CK. Public perception of the risk of blood transfusion. Transfusion. 2000;40(8):1017-1022.

20. Lee DH, Mehta MD, James PD. Differences in the perception of blood transfusion risk between laypeople and physicians. Transfusion. 2003;43(6):772-778.

21. National Heart Lung and BIood Institute. What are the risks of blood transfusion?; 2012. Available from: http://www.nhlbi.nih.gov/health/ health-topics/topics/bt/risks.html. Accessed September 21, 2014.

22. Friedman MT, Avadhani V, Gilmore S, Madrigal E. Blood transfusion in the 21 st century. Discoveries. 2014. Available from: http://www. discoveriesjournals.org/D.2014.01.RA-Dr Friedman.pdf. Accessed September 21, 2014.

23. SchenkerY, Meisel A. Informed consent in clinical care: practical considerations in the effort to achieve ethical goals. JAMA. 2011;305(11): 1130-1131.

24. Widmann FK. Informed consent for blood transfusion: brief historical survey and summary of a conference. Transfusion. 1990;30(5): $460-470$.

25. Institute of Medicine. Crossing the Quality Chasm: A New Health System for the 21st Century. Washington, DC: National Academies Press; 2001. 
26. American Association of Blood Banks. Standards for Blood Banks and Transfusion Services. 27th ed. Bethesda, MD: American Association of Blood Banks; 2011:41.

27. The Joint Commission. Implementation Guide for the Joint Commission Patient Blood Management Performance Measures; 2011:14-17. Available from: http://www.jointcommission.org/assets/1/6/pbm implementation_guide_20110624.pdf. Accessed October 15, 2014.

28. The Joint Commission. Coming Soon: Patient Blood Management Certification Option. The Joint Commission Lab Focus; 2013. Available from: http://www.jointcommission.org/assets/1/18/lab_focus_3_2013. pdf. Accessed September 12, 2014.

29. California Health and Safety Code. The Paul Gann Blood Safety Act; 2014 Available from: http://www.leginfo.ca.gov/cgi-bin/displaycode?section= hsc\&group=01001-02000\&file=1645. Accessed September 12, 2014.

30. Arinsburg SA, Skerrett DL, Friedman MT, Cushing MM. A survey to assess transfusion medicine education needs for clinicians. Transfus Med. 2012;22(1):44-49.

31. O’Brien KL, Champeaux AL, Sundell ZE, Short MW, Roth BJ. Transfusion medicine knowledge in postgraduate year 1 residents. Transfusion. 2010;50(8):1649-1653.

32. Friedman M, Arja W, Batra R, et al. Informed consent for blood transfusion: what do medicine residents tell? What do patients understand? Am J Clin Pathol. 2012;138(4):559-565.

33. Adams KW, Tolich D. Blood transfusion: the patient's experience. Am J Nurs. 2011;111(9):24-30.

34. Davis R, Vincent C, Sud A, et al. Consent to transfusion: patients' and healthcare professionals' attitudes towards the provision of blood transfusion information. Transfus Med. 2012;22(3):167-172.

35. Hart J, Leier B, Nahirniak S. Informed consent for blood transfusion should the possibility of prion risk be included? Transfus Med Rev. 2004;18(3):177-183.

36. Peden AH, Head MW, Ritchie DL, Bell JE, Ironside JW. Preclinical vCJD after blood transfusion in a PRNP codon 129 heterozygous patient Lancet. 2004;364(9433):527-529.

37. New York State Council on Human Blood and Transfusion Services Recommendation for Consent for Blood Transfusion. 2nd ed. Albany, NY: New York State Department of Health; 2008. Available from: http:// www.wadsworth.org/labcert/blood_tissue/forms/consent_transfusion. pdf. Accessed September 17, 2014.

38. Turner P, Williams C. Informed consent: patients listen and read, but what information do they retain? NZ Med J. 2002;115(1164):U218.

39. Eisenstaedt RS, Glanz K, Smith DG, Derstine T. Informed consent for blood transfusion: a regional hospital survey. Transfusion. 1993;33(7): $558-561$

40. Society for the Advancement of Blood Management. 2014. Available from: http://www.sabm.org/mission. Accessed September 14, 2014.

41. McCullough J. Innovation in transfusion medicine and blood banking: documenting the record in 50 years of TRANSFUSION. Transfusion 2010;50(12):2542-2546

42. Ferraris VA, Ferraris SP, Saha SP, et al; Society of Thoracic Surgeons Blood Conservation Guideline Task Force and Society of Cardiovascular Anesthesiologists Special Task Force on Blood Transfusion. Perioperative blood transfusion and blood conservation in cardiac surgery: the society of thoracic surgeons and the society of cardiovascular anesthesiologists clinical practice guideline. Ann Thorac Surg. 2007;83(Suppl 5):S27-S86.

43. Jans Ø, JØrgensen C, Johansson PL. Role of preoperative anemia for risk of transfusion and postoperative morbidity in fast-track hip and knee arthroplasty. Transfusion. 2014;54(3):717-726.

44. Cohen JA, Brecher ME. Preoperative autologous blood donation: benefit or detriment? A mathematical analysis. Transfusion. 1995;35(8): 640-644.

45. Stanton T. Autologous Blood Donations may not Benefit AIS Surgery Patients. American Academy of Orthopaedic Surgeons/American Association of Orthopaedic Surgeons; 2011. Available from: http:// www.aaos.org/news/aaosnow/nov11/clinical11.asp. Accessed September 19, 2014.
46. Kanter MH, van Maanen D, Anders KH, Castro F, Mya WW, Clark K. Preoperative autologous blood donations before elective hysterectomy. JAMA. 1996;276(10):798-801.

47. Billote DB, Glisson SN, Green D, Wixson RL. A prospective, randomized study of preoperative autologous donation for hip replacement surgery. J Bone Joint Surg Am. 2002;84-A(8):1299-1304.

48. Lichtiger B. Directed/designated blood donations: a controversial alternative in transfusion therapy. In: Current Issues in Transfusion Medicine. Houston, TX: The University of Texas MD Anderson Cancer Center; 1993. Available from: http://www3.mdanderson.org/ citm/H93-07.html. Accessed September 19, 2014.

49. Auerbach M, Goodnough LT, Picard D, Maniatis A. The role of intravenous iron in anemia management and transfusion avoidance. Transfusion. 2008;48(5):988-1000.

50. Feagan BG, Wong CJ, Kirkley A, et al. Erythropoietin with iron supplementation to prevent allogeneic blood transfusion in total hip joint arthroplasty. A randomized, controlled trial. Ann Intern Med. 2000;133(11):845-854.

51. Steensma DP. Review: epoetin and darbepoetin reduce need for blood transfusions but increase risk for thrombosis in patients with cancer. ACP J Club. 2008;148(4):7.

52. Fishbane S, Besarab A. Mechanism of increased mortality risk with erythropoietin treatment to higher hemoglobin targets. Clin J Am Soc Nephrol. 2007;2(6):1274-1282.

53. Lindstrom E, Johnstone R. Acute normovolemic hemodilution in a Jehovah's witness patient: a case report. AANA J. 2010;78(4):326-330.

54. Segal JB, Blasco-Colmenares E, Norris EJ, Guallar E. Preoperative acute normovolemic hemodilution: a meta-analysis. Transfusion. 2004;44(5):632-644.

55. Ashworth A, Klein AA. Cell salvage as part of a blood conservation strategy in anaesthesia. Br J Anaesth. 2010;105(4):401-416.

56. Esper SA, Waters JH. Intra-operative cell salvage: a fresh look at the indications and contraindications. Blood Transfus. 2011;9(2):139-147.

57. Muñoz M, Slappendel R, Thomas D. Laboratory characteristics and clinical utility of post-operative cell salvage: washed or unwashed blood transfusion? Blood Transfus. 2011;9(3):248.

58. Voorn VM, Marang-van de Mheen PJ, Wentink MM; LISBOA Study Group, et al. Perceived barriers among physicians for stopping non-cost-effective blood-saving measures in total hip and total knee arthroplasties. Transfusion. 2014;54(10 pt 2):2598-2607.

59. Ozawa S. Patient blood management: use of topical hemostatic and sealant agents. AORN J. 2013;98(5):461-478.

60. Ker K, Edwards P, Perel P, Shakur H, Roberts I. Effect of tranexamic acid on surgical bleeding: systematic review and cumulative metaanalysis. BMJ. 2012;344:e3054.

61. Henry DA, Carless PA, Moxey AJ, et al. Anti-fibrinolytic use for minimising perioperative allogeneic blood transfusion. Cochrane Database Syst Rev. 2011;16(1):CD001886.

62. Brown JR, Birkmeyer NJ, O’Connor GT. Meta-analysis comparing the effectiveness and adverse outcomes of antifibrinolytic agents in cardiac surgery. Circulation. 2007;115(22):2801-2813.

63. Mangano DT, Tudor IC, Dietzel C; Multicenter Study of Perioperative Ischemia Research Group; Ischemia Research and Education Foundation. The risk associated with aprotinin in cardiac surgery. N Engl J Med. 2006;354(4):353-365.

64. US Food and Drug Administration. Early Communication about an Ongoing Safety Review Aprotonin Injection (marketed as Trasylol); 2007. Available from: http://web.archive.org/web/20071030053834/ http://www.fda.gov/cder/drug/early_comm/aprotinin.htm. Accessed September 20, 2014.

65. Bolliger D, Seeberger MD, Tanaka KA. Principles and practice of thromboelastography in clinical coagulation management and transfusion practice. Transfus Med Rev. 2012;26(1):1-13.

66. Thavendiranathan P, Bagai A, Ebidia A, Detsky AS, Choudhry NK. Do blood tests cause anemia in hospitalized patients? The effect of diagnostic phlebotomy on hemoglobin and hematocrit levels. J Gen Intern Med. 2005;20(6):520-524. 
67. Chant C, Wilson G, Friedrich JO. Anemia, transfusion, and phlebotomy practices in critically ill patients with prolonged ICU length of stay: a cohort study. Crit Care. 2006;10(5):R140.

68. Hibbs S, Miles D, Staves J, Murphy MF. Is undertransfusion a problem in modern clinical practice? Transfusion. In press 2014

69. Institute of Medicine. To Err is Human: Building a Safer Health System. Washington, DC: National Academies Press; 1999.

70. The Joint Commission. Facts about the National Patent Safety Goals; 2014. Available from: http://www.jointcommission.org/facts_about_ the_national_patient_safety_goals/. Accessed September 21, 2014.

71. Weiner SJ, Schwartz A, Sharma G, et al. Patient-centered decision making and health care outcomes: an observational study. Ann Intern Med. 2013;158(8):573-579.

72. Trummer UF, Mueller UO, Nowak P, Stidl T, Pelikan JM. Does physician-patient communication that aims at empowering patients improve clinical outcome? A case study. Patient Educ Couns. 2006; 61(2):299-306.

73. Murphy DJ, Pronovost PJ, Lehmann CU, et al. Red blood cell transfusion practices in two surgical intensive care units: a mixed methods assessment of barriers to evidence-based practice. Transfusion. 2014; 54(10 pt 2):2658-2667.

74. Vamvakas EC. Reasons for moving toward a patient-centric paradigm of clinical transfusion medicine practice. Transfusion. 2013;53(4): 888-901.

75. Toy P. Guiding the decision to transfuse: interventions that do and do not work. Arch Pathol Lab Med. 1999;123(7):592-594.

76. Kaur P, Kaur G, Kaur R, Sood T. Assessment of impact of training in improving knowledge of blood transfusion among clinicians. Transfus Med Hemother. 2014;41(3):222-226.

77. Haspel R, Lin Y, Mallick R, et al. Internal medicine residents' knowledge of transfusion medicine: results from the BEST-TEST international needs assessment. Transfusion. 2014;54(Suppl):34A-35A.

78. Rothschild JM, McGurk S, Honour M, et al. Assessment of education and computerized decision support interventions for improving transfusion practice. Transfusion. 2007;47(2):228-239.
79. Goodnough LT, Maggio P, Hadhazy E, et al. Restrictive blood transfusion practices are associated with improved patient outcomes. Transfusion. 2014;54(10 pt 2):2753-2759.

80. Yerrabothala S, Desrosiers KP, Szczepiorkowski ZM, Dunbar NM. Significant reduction in red blood cell transfusions in a general hospital after successful implementation of a restrictive transfusion policy supported by prosepective computerized order auditing. Transfusion. 2014;54(10 pt 2):2640-2645.

81. Cheung D, Lieberman L, Lin Y, Callum J. Consent for blood transfusion: do patients understand the risks and benefits? Transfus Med. 2014;24(5):269-273.

82. Toledo P. Shared decision-making and blood transfusions: is it time to share more? Anesth Analg. 2014;118(6):1151-1153.

83. Institute of Medicine. Unequal Treatment: What Health Care System Administrators Need to Know About Racial and Ethnic Disparities in Healthcare. Washington, DC: National Academies Press; 2002.

84. Cooper LA, Roter DL, Johnson RL, Ford DE, Steinwachs DM, Powe NR. Patient-centered communication, ratings of care, and concordance of patient and physician race. Ann Intern Med. 2003;139(11): 907-915.

85. Dorée C, Stanworth S, Brunskill SJ, Hopewell S, Hyde C, Murphy MF. Where are the systematic reviews? A study of the transfusion medicine evidence base. Transfus Med Rev. 2010;24(4):286-294

86. Wilkinson KL, Brunskill SJ, Dorée C, et al. The clinical effects of red blood cell transfusions: an overview of the randomized controlled trials evidence base. Transfus Med Rev. 2011;25(2):145e-155e.

87. Lorencatto F, Stanworth SJ, Gould NJ. Bridging the research to practice gap in transfusion: the need for a multidisciplinary and evidence-based approach. Transfusion. 2014;54(10 pt 2):2588-2592.

88. Oliver JC, Griffin RL, Hannon T, Marques MB. The success of our patient blood managment program depended on an institution-wide change in transfusion practices. Transfusion. 2014;54(10 pt 2): 2617-2624.

89. Wald ML. Blood Industry Shrinks as Transfusions Decline. New York, NY: The New York Times; 2014.
International Journal of Clinical Transfusion Medicine

\section{Publish your work in this journal}

International Journal of Clinical Transfusion Medicine is an international, peer-reviewed, open access, online journal publishing clinicalexperimental, policy-making and evidence-based practices of all topics pertaining to clinical transfusion medicine. Original research, short reports, reviews, case reports and commentaries are invited.

\section{Dovepress}

The manuscript management system is completely online and includes a very quick and fair peer-review system, which is all easy to use. Visit http://www.dovepress.com/testimonials.php to read real quotes from published authors. 